\title{
The role of cardiopulmonary exercise testing in the initial evaluation of patients wearing intracardiac devices submitted to cardiac rehabilitation
}

Bogdan Caloian ${ }^{1}$, Dana Pop ${ }^{1}$, Gabriel Guşetu ${ }^{1}$, Dumitru Zdrenghea ${ }^{1}$

${ }^{1 .}$ Cardiology - Rehabilitation Department, University of Medicine and Pharmacy “Iuliu Hatieganu”, Cluj-Napoca

Coresponding author Dana POP

E-mail: pop67dana@gmail.com

\begin{abstract}
Cardiopulmonary exercise testing(CPET) is one of the most accurate methods currently used for assessing the exercise capacity of the patients submitted to cardiac rehabilitation programs [1]. It can be used to determine the maximum exercise capacity, to identify the factors that cause a limitation of the patient's functional capacity, to evaluate symptoms triggered by physical exercise and to reveal specific complications related to intracardiac devices that might occur during the physical rehabilitation program.
\end{abstract}

Cardiopulmonary exercise testing(CPET) can be used to determine the maximum exercise capacity, to identify the factors that cause a limitation of the patient's functional capacity, to evaluate symptoms triggered by physical exercise and to reveal specific complications related to intracardiac devices that might occur during the physical rehabilitation program. The rehabilitation of a patient that is wearing an intracardiac device raises some particular issues besides the ones that we meet in a conventionally treated cardiovascular patient. Several clinical studies have shown that the programming mode of the cardiac pacemakers can have a significant influence on the patients exercise capacity, a crucial element of any physical rehabilitation program. CPET is one of the most accurate and comprehensive methods for the evaluation of the pacemaker-wearing patients, being able to optimize their functional capacity and, therefore, should be recommended in all patients before inclusion in cardiac exercise rehabilitation programs. Keywords: Cardiac rehabilitation, Intracardiac devices, Cardiopulmonary exercise testing.

\section{Evaluation of the patient's maximum exercise capacity}

This evaluation method is able to determine parameters like $\mathrm{VO}_{2}$ max (the maximum oxygen uptake of the patient during exercise), the ventilatory threshold (VT - the moment when the metabolism switches from aerobic to anaerobic), the maximum exercise capacity estimated in metabolic equivalents (METs), the respiratory exchange ratio, all of them being important indicators of the patient's functional capacity $[2,3]$. The current clinical practice guidelines in terms of cardiac rehabilitation recommend that physical exercise should be prescribed only after determining the $\mathrm{VO}_{2}$ max, which is considered to be the most accurate indicator of the patient's exercise capacity, as shown in a review article published by Price JK et al in European Journal of Preventive Cardiology in 2016 [4].

The rehabilitation program should be started with moderate intensity training (40-50\% of $\mathrm{VO}_{2}$ max) and increased progressively up to $70-80 \%$ (high intensity training). An alternative parameter to $\mathrm{VO}_{2}$ max is the heart rate reserve (HRR), which can also be determined by standard exercise testing.

Another clinically significant result returned by CPET is the estimation of functional capacity in metabolic equivalents (METs), which can be used to classify heart failure into NYHA classes and establish the indication for both cardiac resynchronization therapy and cardiac defibrillator implantation.

\section{Identification of the factors that reduce the exercise capacity}

CPET can also be used to distinguish between different pathological conditions that cause a limitation of the exercise capacity: heart failure, respiratory diseases or physical deconditioning.

$\mathrm{VO}_{2}$ max, a parameter determined only by CPET, and $\mathrm{VO} 2 / \mathrm{HR}$ (HR=heart rate) are direct predictors of the left ventricular stroke volume and of the cardiac output and can be used to diagnose cardiacrelated causes of low functional capacity or to establish the severity of the symptoms in patients 
with known heart failure [5]. $\mathrm{A} \mathrm{VO}_{2}$ max below $50 \%$ and a VT at

under $40 \%$ of the predicted values are indicators for severe impairment of the exercise capacity.

On the other hand, the CPET evaluates the efficiency of the respiratory gas changes by calculating two slopes: $\mathrm{Ve} / \mathrm{VCO}_{2}$ and $\mathrm{Ve} / \mathrm{VO}_{2}(\mathrm{Ve}$ - tidal volume, VCO2 - carbon dioxide volume, VO2 - oxygen volume) and, as a consequence, is also able to detect respiratory causes of poor exercise capacity $[6,7,8]$.

The main causes of reduced exercise capacity and the modified CPET parameters for each one of them are presented in table 1.

\begin{tabular}{|l|c|c|c|}
\hline \multicolumn{1}{|c|}{ Causes of reduced exercise } & \multicolumn{1}{|c|}{$\begin{array}{c}\text { Peak } \\
\text { capacity }\end{array}$} & $\begin{array}{c}\text { Anaerobic } \\
\text { threshold }\end{array}$ & $\begin{array}{c}\text { Breathing } \\
\text { reserve }\end{array}$ \\
\hline $\begin{array}{l}\text { Circulatory impairment (heart } \\
\text { disease) }\end{array}$ & $\square$ & $\square$ & Normal \\
\hline $\begin{array}{l}\text { Respiratory impairment } \\
\text { (pulmonary disease) }\end{array}$ & $\square$ & Normal & \\
\hline $\begin{array}{l}\text { Mixed lesions (both cardiac and } \\
\text { pulmonary) }\end{array}$ & $\square$ & $\square$ & $\square$ \\
\hline $\begin{array}{l}\text { Deconditioning / Ischemic heart } \\
\text { disease }\end{array}$ & $\square$ & Normal & Normal \\
\hline Anxiety / Obesity / Mild disease & Normal & Normal & Normal \\
\hline
\end{tabular}

Table 1. Differential diagnosis of reduced exercise capacity by CPET.

\section{Diagnosis of symptoms triggered by effort}

It can also provide the same valuable information as a standard exercise ECG test: symptoms caused by exercise (angina, palpitations, syncope), ECG changes suggestive for ischemic heart disease, arrhythmias (extra beats, atrial fibrillation, ventricular tachycardia), abnormal blood pressure response to physical exercise [9].

The diagnose of ischemic heart disease can be difficult in patients with paced rhythm because the abnormal ventricular repolarization caused by pacing hides the typical ischemic ECG changes (ST segment deviation, $\mathrm{T}$ wave inversion). In patients with a high percentage of right ventricular pacing, the "T wave memory" sign can be present, meaning that the abnormal ventricular repolarization (negative $\mathrm{T}$ wave) persists even after an intrinsic ventricular depolarization. In these cases, a different evaluation method (imaging method) for myocardial ischemia might be required [10].

Palpitations during physical exercise can be benign in young patients, in the absence of structural heart disease, being caused by sinus tachycardia, but suggest a negative prognostic in patients with structural heart disease, especially when they are caused by sustained ventricular arrhythmias.

Syncope that occurs during effort has significant clinical implications, potential causes being: supraventricular tachyarrhythmias with a very high heart rate, especially in the presence of ventricular preexcitation, sustained ventricular tachyarrhythmias, severe aortic or mitral stenosis, obstructive hypertrophic cardiomyopathy, Brugada syndrome, long or short QT syndrome, polymorphic cathecholaminergic ventricular tachycardia.

\section{Specific complications related to intracardiac devices}

The optimization of the medical care in most developed countries has determined an important increase in the population life-expectancy, the infectious diseases being replaced with degenerative cardiovascular diseases as the main cause of morbidity and mortality [11]. Patients benefit nowadays from interventional cardiology procedures and device therapy (cardiac pacemakers and internal defibrillators implantation, cardiac resynchronization therapy with biventricular pacing), therapeutic measures that must be followed by cardiac rehabilitation programs for optimal results [12].

The rehabilitation of a patient that is wearing an intracardiac device raises some particular issues besides the ones that we meet in a conventionally treated cardiovascular patient [13]. Pacemakers and internal defibrillators are capable of adjusting the heart rhythm to help the patient adapt to physical training: in patients with bradyarrhythmias, they prevent the heart rate to drop under a certain limit (usually 60-70 beats/min), in patients with chronotropic incompetence (failure to increase the heart rate during exercise) some pacemakers have the option to detect the level of exercise performed by the patient and to increase the heart rate accordingly (rate responsive function), some pacemakers are programmed with algorithms that favor the intrinsic activation of the ventricles during exercise, activation that produces a much more effective contraction compared to the activation delivered by the right ventricular apical pacing, dual-chamber pacemakers maintain the atrioventricular synchronism in patients in sinus 
rhythm (each atrial contraction followed by a ventricular contraction), internal defibrillators detect life-threatening arrhythmias and deliver specific electrical therapies (anti-tachycardia pacing, internal electrical shock) $[14,15,16]$.

\begin{tabular}{|c|c|c|}
\hline $\begin{array}{l}\text { Modified } \\
\text { CPET } \\
\text { parameter } \\
\text { during effort }\end{array}$ & Device type & Possible cause \\
\hline Bradycardia & $\begin{array}{l}\text { AAI, VVI, } \\
\text { DDD } \square \mathrm{R}\end{array}$ & $\begin{array}{l}\text { Pacing deficit } \\
\text { Loss of ventricular } \\
\text { capture } \\
\text { Oversensing }\end{array}$ \\
\hline $\begin{array}{l}\text { Excessive/inap } \\
\text { propriate } \\
\text { tachycardia }\end{array}$ & $\mathrm{DDD} \square \mathrm{R}$ & $\begin{array}{l}\text { Oversensing of atrial } \\
\text { activity } \\
\text { Undersensing of } \\
\text { ventricular activity } \\
\text { Pacemaker-induced } \\
\text { tachycardia }\end{array}$ \\
\hline $\begin{array}{l}\text { Atrioventricula } \\
\text { r block }\end{array}$ & AAI $\square \mathrm{R}$ & $\begin{array}{l}\text { Atrioventricular } \\
\text { conduction abnormality } \\
\text { newly } \\
\text { acquired/undiagnosed at } \\
\text { the moment of } \\
\text { pacemaker implant }\end{array}$ \\
\hline $\begin{array}{l}\text { Lack of } \\
\text { chronotropic } \\
\text { response }\end{array}$ & $\begin{array}{l}\text { AAI, VVI, } \\
\text { DDD }\end{array}$ & $\begin{array}{l}\text { Rate responsive function } \\
\text { not activated / not } \\
\text { correctly programmed }\end{array}$ \\
\hline $\begin{array}{l}\text { Antitachycardi } \\
\text { a } \\
\text { pacing/Internal } \\
\text { electrical shock }\end{array}$ & ICD, CRT-D & $\begin{array}{l}\text { Oversensing of } \\
\text { ventricular activity } \\
\text { Ventricular tachycardia } \\
\text { detection interval set too } \\
\text { low } \\
\text { Misdiagnosticated } \\
\text { supraventricular } \\
\text { arrhythmias with } \\
\text { functional bundle branch } \\
\text { block }\end{array}$ \\
\hline $\begin{array}{l}\text { Untreated } \\
\text { sustained } \\
\text { ventricular } \\
\text { arrhythmias }\end{array}$ & ICD, CRT-D & $\begin{array}{l}\text { Undersensing of } \\
\text { ventricular activity } \\
\text { Ventricular tachycardia } \\
\text { detection interval set too } \\
\text { high }\end{array}$ \\
\hline $\begin{array}{l}\text { Loss of } \\
\text { interventricula } \\
\text { r synchronism } \\
\text { (biventricular } \\
\text { pacing } \\
\text { replaced with } \\
\text { intrinsic } \\
\text { cardiac } \\
\text { rhythm) }\end{array}$ & $\begin{array}{l}\text { CRT-P, } \\
\text { CRT-D }\end{array}$ & $\begin{array}{l}\text { AV delay programmed } \\
\text { too long } \\
\text { Incomplete blockage of } \\
\text { AV node }\end{array}$ \\
\hline $\begin{array}{l}\text { Unchanged } \\
\text { VO }_{2} \text { max, VT, } \\
\text { VO } / \text { HR ratio } \\
\text { after CRT }\end{array}$ & $\begin{array}{l}\text { CRT-P, } \\
\text { CRT-D }\end{array}$ & $\begin{array}{l}\text { Non-responders to } \\
\text { cardiac } \\
\text { resynchronization } \\
\text { therapy }\end{array}$ \\
\hline
\end{tabular}

During physical rehabilitation, device wearing patients, can experience several complications either caused by device malfunctioning or that interfere with the normal activity of the devices (table 2).

Table 2. Potential malfunctions of the intracardiac devices during physical exercise detectable by cardiopulmonary exercise testing. $\mathrm{CPET}=$ cardiopulmonary exercise testing; $\mathrm{AAI}=$ single chamber atrial pacemaker; $\mathrm{VVI}=$ single chamber ventricular pacemaker; $\mathrm{DDD}=$ dual chamber atrio-ventricular pacing; $\mathrm{R}=$ rate responsive; ICD=implantable cardiac defibrillator; $\mathrm{CRT}-\mathrm{P}=$ cardiac resynchronization therapy pacing only; CRT-D=cardiac resynchronization therapy with defibrillation; $\mathrm{VT}=$ ventilator threshold; VO2= volume of oxygen; HR=heart rate

The movements of the patients during exercise cause artefacts that can be misinterpreted by the devices as being real cardiac depolarization and, as a consequence, pacemakers stop generating electrical impulses, the heart rate drops and the patient experiences a syncope (over sensing) and implantable defibrillators deliver inappropriate antitachycardia pacing or even electrical shocks [17]. Sometimes a normal sinus tachycardia, developed by the patient as a physiological response to exercise, can reach the lower limit of the ventricular tachycardia detection interval of the defibrillator, which responds by initiating the specific electrical therapies. To prevent these malfunctions, the devices of the patients submitted to physical rehabilitation have to be reprogrammed accordingly after establishing their maximum heart rate during the exercise test $[18,19]$.

Several clinical studies have shown that the programming mode of the cardiac pacemakers can also have a significant influence on the patients exercise capacity, a crucial element of any physical rehabilitation program (table 3) [20, 21, 22]. The most frequently implanted pacemakers are singlechamber (VVI - right ventricular pacing) and dualchamber (DDD - right atrial and right ventricular pacing), with or without the rate response function activated. Cardiac resynchronization therapy (triple-chamber pacing - right atrial, right ventricular and left ventricular pacing) is reserved only for patients with severe heart failure (severe left ventricular systolic dysfunction) in the presence of interventricular dissynchronism (wide QRS 
complex) and is less frequently used, given the complex implantation procedure and high costs.

A meta-analysis published by Carsten W. Israel in 2015 reviewed the clinical trials that compared atrial and ventricular pacing modes in terms of quality of life, symptoms of heart failure and exercise capacity. While dual-chamber pacing, especially DDDR, has proven to be superior to single-chamber right ventricular pacing in terms of maximum exercise capacity, studies that compared DDD and VVIR pacing modes returned discordant results [23]. This proves that the activation of the rate responsive function of the single-chamber ventricular pacemakers has an effect on the exercise capacity of similar importance as the atrioventricular synchronism maintained by the dual chamber atrioventricular pacing. In other words, the activation of a pacemaker programming option, that is not activated by default in all pacemakers, is able to increase the cardiac output by the same percent as an efficient atrial contraction, approximately $20 \%$.

A similar conclusion was drawn by the authors of a clinical study published in 2017 in Europace (Palmisano et al.) after evaluating the exercise capacity of 60 patients with biventricular pacing for cardiac resynchronization therapy, showing that by activating the rate responsive function of the pacemaker, a significant improvement of the functional capacity can be achieved [24].

Single chamber atrial pacemakers (AAI or AAIR) can be used for the treatment of sick sinus syndrome in patients with preserved atrioventricular conduction. The use of passive fixation leads might be preferred over active fixation ones, especially in elderly, because of the lower risk of atrial wall perforation and cardiac tamponade, but this implies a higher risk of lead dislocation during effort, which can cause sudden heart rate drop, cerebral hypoperfusion and syncope [25]. This cathegory of patients must be also evaluated by cardiopulmonary exercise testing prior to inclusion in a cardiac exercise rehabilitation program.

Another relatively frequently encountered condition is the so called pacemaker syndrome, which is caused by the atrioventricular dyssynchrony met in patients in sinus rhythm wearing a single chamber ventricular pacemaker (VVI). In this case, the contraction of the atria against closed atrioventricular valves causes palpitations, fatigue and reduced exercise capacity due to the loss of atrial contribution to the cardiac output. Upgrading to dual chamber pacing (DDD) can relieve symptoms and significantly ameliorate functional capacity.

In conclusion, cardiopulmonary exercise testing is one of the most accurate and comprehensive methods for the evaluation of the pacemakerwearing patients, being able to optimize their functional capacity and detect potential complications during effort and, therefore, should be recommended in all patients before inclusion in cardiac exercise rehabilitation programs.

\begin{tabular}{|c|c|c|}
\hline Parameter & $\begin{array}{l}\text { Pacema } \\
\text { ker type }\end{array}$ & Description \\
\hline Pacing mode & DDD & $\begin{array}{l}\text { Dual chamber pacemakers } \\
\text { can be programmed in AAI, } \\
\text { VVI, VDD modes }\end{array}$ \\
\hline Minimum HR & $\begin{array}{l}\text { AAI, } \\
\text { VVI, } \\
\text { DDD }\end{array}$ & $\begin{array}{l}\text { Usualy set at } 60-70 \mathrm{bpm} \\
\text { In most ICD } 40 \mathrm{bpm}\end{array}$ \\
\hline $\begin{array}{l}\text { Rate } \\
\text { responsive } \\
\text { function }\end{array}$ & $\begin{array}{l}\text { AAIR, } \\
\text { VVIR, } \\
\text { DDDR }\end{array}$ & $\begin{array}{l}\text { Can be activated/deactivated } \\
\text { (not activated by default in } \\
\text { all pacemakers) }\end{array}$ \\
\hline $\begin{array}{l}\text { RR upper } \\
\text { rate }\end{array}$ & $\begin{array}{l}\text { AAIR, } \\
\text { VVIR, } \\
\text { DDDR }\end{array}$ & $\begin{array}{l}\text { The maximum paced heart } \\
\text { rate that can be achieved at } \\
\text { peak exercise (usualy 110- } \\
150 \mathrm{bpm} \text { ) }\end{array}$ \\
\hline $\begin{array}{l}\text { RR function } \\
\text { response time }\end{array}$ & $\begin{array}{l}\text { AAIR, } \\
\text { VVIR, } \\
\text { DDDR }\end{array}$ & $\begin{array}{l}\text { The speed of heart rate } \\
\text { increase during exercise (can } \\
\text { be set to slow/ medium/ fast) }\end{array}$ \\
\hline $\begin{array}{l}\text { Maximum } \\
\text { tracking rate }\end{array}$ & DDD & $\begin{array}{l}\text { The maximum intrinsec atrial } \\
\text { rate transmited } 1: 1 \text { to the } \\
\text { ventricles }\end{array}$ \\
\hline AV delay & $\begin{array}{l}\text { DDD, } \\
\text { CRT-P, } \\
\text { CRT-D }\end{array}$ & $\begin{array}{l}\text { In DDD - promotes intrinsec } \\
\text { activation of the ventricles } \\
\text { In CRT - keeps the patient on } \\
\text { resynchronization paced } \\
\text { rhythm }\end{array}$ \\
\hline PVARP & $\begin{array}{l}\text { DDD, } \\
\text { CRT-P, } \\
\text { CRT-D }\end{array}$ & $\begin{array}{l}\text { Influences the AV delay and } \\
\text { the 2:1 block rate, protects } \\
\text { against pacemaker mediated } \\
\text { tachycardia }\end{array}$ \\
\hline
\end{tabular}

Table 3. Adjustable pacemaker parameters that can influence the patients exercise capacity.

$\mathrm{AAI}=$ single chamber atrial pacemaker; $\mathrm{VVI}=$ single chamber ventricular pacemaker; $\mathrm{DDD}=$ dual chamber atrio-ventricular pacing; $\mathrm{RR}=$ rate responsive; ICD=implantable cardiac defibrillator; $\mathrm{CRT}-\mathrm{P}=$ cardiac resynchronization therapy pacing only; CRT-D=cardiac resynchronization therapy with defibrillation; AV=atrioventricular; PVARP=post ventricular atrial refractory period. 


\section{References}

1. Albouaini $\mathrm{K}$, Egred $\mathrm{M}$, Alahmar A. Cardiopulmonary exercise testing and its application. Postgraduate Medical Journal. 2007;83(985):675-682. doi:10.1136/hrt.2007.121558.

2. Joint Statement of the American Thoracic Society (ATS) and the American College of Chest Physicians (ACCP). ATS/ACCP Statement on Cardiopulmonary Exercise Testing. Am J Respir Crit Care Med. 2003 Jan 15;167(2):211-77.

DOI:10.1164/rccm.167.2.211.

3. Haddad HA, Fonteles RL, Ricardo S, et al. Cardiopulmonary Exercise Test: Background, Applicability and Interpretation. Arq. Bras. Cardiol. [Internet]. 2016 Nov [cited 2017 Oct 21]; 107(5): 467-481. http://dx.doi.org/10.5935/abc.20160171.

4. Price KJ, Gordon BA, Bird SR et al. A review of guidelines for cardiac rehabilitation exercise programmes: Is there an international consensus? European Journal of Preventive Cardiology 2016; 23(16):1715 - 1733. DOI: 10.1177/2047487316657669.

5. Datta D, Normandin E, ZuWallack R. Cardiopulmonary exercise testing in the assessment of exertional dyspnea. Ann Thorac Med 2015;10: 77-86. DOI: 10.4103/18171737.151438.

6. Arena R, Sietsema KE. Cardiopulmonary Exercise Testing in the Clinical Evaluation of Patients with Heart and Lung Disease. Circulation. 2011;123: 668-680. DOI: https://doi.org/10.1161/CIRCULATIONAHA. 109.914788.

7. Christina Triantafillidou, Effrosyni Manali, Panagiotis Lyberopoulos, et al., "The Role of Cardiopulmonary Exercise Test in IPF Prognosis,” Pulmonary Medicine, vol. 2013, Article ID 514817, 9 pages, 2013. doi:10.1155/2013/514817.

8. Milani RV, Lavie CJ, Mehra MR. Cardiopulmonary Exercise Testing. How Do We Differentiate the Cause of Dyspnea? Circulation. 2004;110:e27-e31. doi: 10.1161/01.CIR.0000136811.45524.2F

9. Belardinelli R, Lacalaprice F, Tiano L, et al. Cardiopulmonary exercise testing is more accurate than ECG-stress testing in diagnosing myocardial ischemia in subjects with chest pain. Int J Cardiol. 2014 Jun 15;174(2):33742. doi: 10.1016/j.ijcard.2014.04.102.

10. Dădârlat A, Zdrenghea D, Pop D. Role of Duke treadmill score in the diagnosis of ischemic heart disease in women. Rom J Intern Med. 2015;53(2):146-52.

11. Lozano R, Naghavi M, Foreman K, et al. Global and regional mortality from 235 causes of death for 20 age groups in 1990 and 2010: A systematic analysis for the Global Burden of Disease Study 2010. Lancet. 2012 Dec 15;380(9859):2095-128. doi: 10.1016/S01406736(12)61728-0.

12. Dardas T, Li Y, Reed DS, et al. Incremental and independent value of cardiopulmonary exercise test measures and the Seattle Heart Failure Model for prediction of risk in patients with heart failure $J$ Heart Lung Transplant 2015;34:1017-1023.

13. Reibis RK, Kamke W, Langheim E, et al. Rehabilitation of patients with cardiac pacemakers and implanted cardioverterdefibrillators: recommendations for training, physiotherapeutic procedures and reemployment. Dtsch Med Wochenschr. 2010 Apr;135(15):759-64. doi: 10.1055/s-00301251930.

14. Haennel RG. Exercise Rehabilitation for Chronic Heart Failure Patients with Cardiac Device Implants. Cardiopulmonary Physical Therapy Journal. 2012;23(3):23-28.

15. Iliou MC, Blanchard JC, Lamar-Tanguy A, et al. Cardiac rehabilitation in patients with pacemakers and implantable cardioverter defibrillators. Monaldi Arch Chest Dis. 2016 Oct 14;86(1-2):756. doi: 10.4081/monaldi.2016.756.

16. Dendale P., Frederix I. (2017) Case-Based Learning Cardiac Rehabilitation Pacemaker Implantation. In: Niebauer J. (eds) Cardiac Rehabilitation Manual. Springer, Cham. DOI: https://doi.org/10.1007/978-3-319-477381_14.

17. Safavi-Naeini P, Saeed M. Pacemaker Troubleshooting: Common Clinical Scenarios. Texas Heart Institute Journal. 2016;43(5):415-418. doi:10.14503/THIJ-165918. 
18. Brignole M, Auricchio A, Baron-Esquivias G, et al. 2013 ESC Guidelines on cardiac pacing and cardiac resynchronization therapy: The Task Force on cardiac pacing and resynchronization therapy of the European Society of Cardiology (ESC). Developed in collaboration with the European Heart Rhythm Association (EHRA) Eur Heart J. 2013;34(29):2281-329.

19. Lau CP, Siu CW. Pacing technology: advances in pacing threshold management. J Zhejiang Univ Sci B. 2010;11(8):634-8.

20. G.A. Lamas, K.L. Lee, M.O. Sweeney, et al. Ventricular pacing or dual-chamber pacing for sinus-node dysfunction. $N$ Engl $J$ Med, 2002;346:1854-1862.

21. G.A. Lamas, J.D. Knight, M.O. Sweeney, et al. Impact of rate-modulated pacing on quality of life and exercise capacity - evidence from the Advanced Elements of Pacing Randomized Controlled Trial (ADEPT). Heart Rhythm, 2007;4:1125-1132.

22. Prech M, Grygier M, Mitkowski P, et al. Effect of Restoration of AV Synchrony on Stroke Volume, Exercise Capacity, and Quality-ofLife: Can We Predict the Beneficial Effect of a Pacemaker Upgrade? Pacing and Clinical Electrophysiology, 2001;24: 302-307. doi:10.1046/j.1460-9592.2001.t01-1-00302.x.

23. Israel WC, Clinical Trials of Atrial and Ventricular Pacing Modes. In De Kenneth A, Ellenbogen BL, Wilkoff G. Clinical Cardiac Pacing, Defibrillation and Resynchronization Therapy, $4^{\text {th }}$ ed. Elsevier 2015.

24. Palmisano P, Aspromonte V, Ammendola E, Effect of fixed-rate vs. rate-RESPONSIve pacing on exercise capacity in patients with permanent, refractory atrial fibrillation and left ventricular dysfunction treated with atrioventricular junction aBLation and bivEntricular pacing (RESPONSIBLE): a prospective, multicentre, randomized, singleblind study. Europace (2017) 19, 414-420. doi:10.1093/europace/euw035.

25. Ghani A, Delnoy PPHM, Ramdat Misier AR, et al. Incidence of lead dislodgement, malfunction and perforation during the first year following device implantation. Netherlands Heart Journal. 2014;22(6):286291. doi:10.1007/s12471-014-0556-6. 